\title{
The Visual Status of Diabetics on Renal Replacement Therapy (RRT)
}

\author{
C. J. MACEWEN*, T. BARRIE*, B. J. R. JUNOR**, M. A. McMILLAN** and \\ J. D. BRIGGS** \\ Glasgow
}

\begin{abstract}
Summary
The visual status of 48 patients with end-stage diabetic nephropathy who were undergoing treatment either by dialysis or transplantation was assessed. At the time of starting dialysis, the vision was good in 27 (56 per cent), impaired in 7 ( 15 per cent) and of navigating standard only in 12 (25 per cent) while the remaining 2 (4 per cent) had no useful vision. During the time on dialysis and/or following transplantation, vision improved in 6 patients ( 12 per cent), deteriorated in 9 (19 per cent) and remained unchanged in 33 (69 per cent). Changes in the degree of retinopathy in the 96 eyes resulting either from treatment of the renal failure or laser therapy were noted. The reasons for any changes in vision and the effect of ophthalmic treatment will be discussed.
\end{abstract}

Micro-angiopathy is responsible for the nephropathy and retinopathy of diabetes mellitus. The combination of progressive renal failure and visual loss is a well recognised entity which has been called, 'The Diabetic Renal-Retinal Syndrome' ${ }^{\prime}$ and the diabetic with end-stage renal failure commonly has, in addition, retinopathy and a variable degree of visual loss.

Haemodialysis (HD), continuous ambulatory peritoneal dialysis (CAPD) and successful renal transplantation are grouped together under the heading of renal replacement therapy (RRT). Previous studies of patients being treated by RRT have shown that between 78 per cent and 100 per cent had retinopathy and 23 per cent to 50 per cent were blind. ${ }^{2-9}$ In the majority of those on CAPD and with transplants the mode of treatment of their renal failure had little effect on visual function while those on HD generally suffered further visual deterioration.
Little attention has been paid to the effect of ophthalmic treatment on the visual status during RRT. In previous studies the application of laser photocoagulation was either not documented, ${ }^{2-5}$ considered not to alter significantly the visual outcome,,${ }^{6,7}$ or lacked specific details of the effect of treatment. ${ }^{8,9}$ Also the type of retinopathy being treated was not clearly delineated in many of these studies.

We have looked at the ocular status and results of ophthalmic treatment in a series of 48 patients during RRT for diabetic nephropathy in an area where most diabetic patients, regardless of visual function, are offered treatment for renal failure.

\section{Patients and Methods}

Between January 1979 and July 1986 sixty-one diabetic patients were treated by RRT at the Western Infirmary, Glasgow. Thirteen were excluded

From *Department of Ophthalmology, Gartnavel General Hospital, Glasgow and ** Renal Unit, Western Infirmary, Glasgow.

Correspondence to: Caroline J MacEwen FRCS, Department of Ophthalmology, Gartnaval General Hospital, Glasgow. 
because of inadequate evidence that renal failure was due to diabetic nephropathy. Thus 48 patients remained to form the study group.

Six patients were on HD, 22 on CAPD and 20 had functioning transplants at the end of the study. Details of visual acuity and degree of retinopathy at the time of starting dialysis and any changes in these during the study period were retrieved from the case notes.

In assessing visual function the patients were considered as individuals rather than taking each eye separately. Group 1, 'good vision', 6/6-6/12; Group 2, 'impaired vision', 6/18-6/36; Group 3, 'navigating vision', $6 / 60$ - hand movements (HM) and Group 4, 'blind', perception of light (P of L) to no perception of light (NP of L).

It was felt more appropriate to consider the retinopathy in each eye separately: Group A, 'background changes only'; Group B, 'Maculopathy'; Group C, 'active' (pre-proliferative or proliferative', eyes with vitreous haemorrhage were also included in this group); Group D, 'stable treated proliferative', and Group E 'end-stage proliferative' (failed treatment or no treatment).

The reasons for alteration in vision and efficacy of ophthalmic treatment were examined.

\section{Results}

There were 16 females and 32 males of whom 36 were Type I diabetics and 12 were Type II. At commencement of RRT the average age of patients was 46.2 years (range 20 to 64 years) and the mean duration of diabetes was 22 years (range 6 to 40 years). In 28 cases there was specific mention by the referring physician of poor metabolic control. The number of patients receiving each form of treatment was as follows: CAPD 22, HD 6 and 20 had functioning renal transplants. The mean duration of treatment for the 22 CAPD patients was 16.7 months, for the 6 on HD, 17.1 months while the mean duration of graft survival for the 20 transplanted patients was 27.4 months. The transplanted patients had previously been dialysed for a mean of 13.9 months (1 HD, 19 CAPD). One patient had received his second transplant and 3 in the CAPD group had previously had an unsuccessful transplant. Fourteen patients died during the study period (1 HD, 12 CAPD and 1 transplanted).

\section{Visual Function}

The patients were grouped according to visual function. At the time of commencing RRT there were 27 patients ( 56 per cent) in Group 1 , 'good vision', $6 / 6$ to $6 / 12 ; 7$ patients $(15$ per cent) in Group 2, 'impaired vision', 6/18-6/36; 12 patients ( 25 per cent) in Group 3, 'navigating vision', $6 / 60-\mathrm{HM}$ and 2 patients (4 per cent) in Group 4, 'blind', perception of light to no perception of light. At the end of the study there were 25 patients ( 52 per cent) in Group 1, 9 patients (19 per cent) in Group 2, 8 patients (17 per cent) in Group 3 and 6 patients (12 per cent) in Group 4.

Thus over the period of RRT the vision of 33 patients (69 per cent) remained stable, 6 (12 per cent) improved and 9 (19 per cent) deteriorated (scattergram).

One patient's vision improved following surgery for removal of vitreous haemorrhage, one after spontaneous clearance of vitreous haemorrhage, another 2 following cataract extraction and the remaining 2 improved after laser treatment with improvement of macular function. Deterioration was due to progression of retinopathy to rubeotic glaucoma in 3 cases, following unsuccessful vitreous surgery in 2 cases, increasing cataract in another 2 and increasing maculopathy in the remaining patient.

Of the 14 patients who died, all remained visually stable from the beginning of the study until the time of death. Nine were in Group 1, 3 in Group 2 and 1 in Group 3.

\section{Retinopathy and Treatment}

Retinopathy was reviewed with respect to individual eyes (Table I). During the time of RRT 2 eyes regressed from preproliferative, 'active', changes to 'background'; 3 deteriorated from 'active' retinopathy to 'end-stage'; 13 were modified by laser treatment from 'active' to 'stable', and 77 eyes did not change with respect to retinopathy.

There was no progression to proliferation in the eyes with background changes or maculopathy. All eyes with active neovascularisation received laser treatment. Thirty-three eyes had been satisfactorily treated for active retinopathy in the past and they all remained under observation: no treatment being required. As would be expected the eyes in Group E 'end-stage', remained unchanged. 
VISUAL FUNCTION OF PATIENTS BEFORE AND DURING RRT

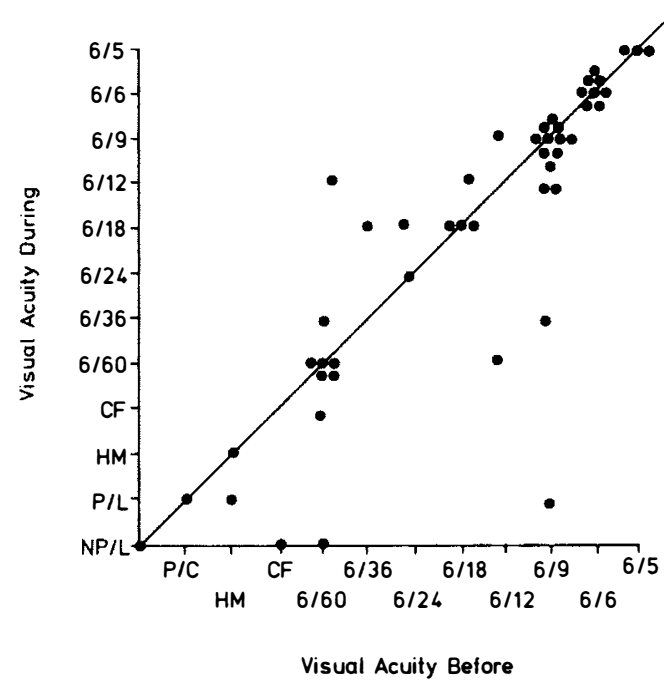

Fig. 1. Graph illustrating the visual function before $R R T$ and at the end of the study.

\section{Visual Results and Treatment Given Laser}

The 16 eyes with background changes requiring no laser treatment retained good acuities (Table II). Eleven of these eyes had vision in the Group 1 category and the remainder had reduced acuities because of amblyopia in one case, cataract in 3 cases and long standing traumatic retinal detachment in the remaining case.

Twelve eyes were too advanced to benefit from laser therapy when first seen; of the 7 in Group 3, 4 had maculopathy and 3 traction retinal detachment and all 5 in Group 4 had rubeotic glaucoma.

The other 68 eyes all received laser treatment at some point. Of these, 29 retained vision in the Group 1, 6/6-6-12 range; including one who had spontaneous clearance of vitreous haemorrhage and one following vitreous surgery. Seven eyes had 'impaired vision' in the Group 2 range. Four of these had minimal changes of maculopathy, 2 had excessive gliosis and one had recurrent haemorrhage. Of the 19 eyes in Group 3, the reduction in vision was due to maculopathy in 12 cases, cataracts in 5 cases and vitreous haemorrhage in 2 . Thirteen eyes which had undergone laser treatment finished with very poor vision in the Group 4 range. Seven of these had rubeotic glaucoma, 5 traction retinal detachment and one maculopathy. In 9 cases particular problems accounted for the lack of success in treatment. In 5 cases, the patients were initially seen at a stage when extensive gliosis and aggressive new vessel were present, but despite this treatment was attempted. In a further three cases, recurrent vitreous haemorrhage prevented adequate treatment at the appropriate time and in one further case recurrent illness prevented the patient from attending, with subsequent loss of useful vision in one eye. The four remaining eyes were seen at the appropriate time; however extensive treatment with argon, xenon and cryo-therapy was not adequate to prevent the progression of retinopathy.

\section{Surgery}

Four vitrectomies were performed. One was successful, 2 advanced to rubeotic glaucoma after surgery and the other was considered an inoperable retinal detachment at the time of surgery. All patients had pre-operative ultrasound and electro-physiology. Two operations were performed for long standing vitreous haemorrhage (longer than 1 year) and 2 for haemorrhage with associated retinal detachment in an only eye. One had surgery prior to starting RRT and the other 3 were carried out while the patients were maintained on CAPD. Once RRT had been commenced surgery was only considered if the prognosis for life was good and the patient had no useful vision.

Table I Retinopathy grading in each eye at the beginning and end of the study

\begin{tabular}{lcc}
\hline & Beginning & End \\
\hline $\begin{array}{l}\text { Group A } \\
\text { Background }\end{array}$ & 14 & 16 \\
$\begin{array}{c}\text { Group B } \\
\text { Maculopathy }\end{array}$ & 9 & 9 \\
$\begin{array}{c}\text { Group C } \\
\text { Active }\end{array}$ & 21 & $3^{*}$ \\
$\begin{array}{c}\text { Group D } \\
\text { Stable } \\
\text { Group E } \\
\text { End-Stage }\end{array}$ & 33 & 46 \\
\hline
\end{tabular}

* Presumed active due to persisting vitreous haemorrhage precluding treatment. 
Table II Final visual function in relation to laser therapy applied

\begin{tabular}{lccc}
\hline & & \multicolumn{2}{c}{ No laser } \\
\cline { 3 - 4 } & Laser & $\begin{array}{c}\text { Not } \\
\text { required }\end{array}$ & $\begin{array}{c}\text { Too } \\
\text { advanced }\end{array}$ \\
\hline Group 1 & 29 & 11 & 0 \\
Group 2 & 7 & 3 & 0 \\
Group 3 & 19 & 1 & 7 \\
Group 4 & 13 & 1 & 5 \\
\hline Total & 68 & 16 & 12 \\
\hline
\end{tabular}

\section{Other Ocular Conditions}

Other ocular complications of diabetes mellitus and treatment for renal failure occurred in 17 eyes (Table III).

\section{Discussion}

Since the introduction of insulin 60 years ago and with improving standards of diabetic care the quality and duration of life for the diabetic has improved. There remain, however, important long term complications. The major causes of morbidity and mortality are accelerated arteriosclerosis of the coronary and cerebral circulations and microangiopathy affecting the kidney and retina. ${ }^{10-13}$

The pathogenesis of diabetic microangiopathy is complex; basement membrane thickening, mural cell dysfunction and capillary occlusion all play a part. ${ }^{14-17}$ Alteration in blood rheology with abnormal platelet adhesion and aggregation, ${ }^{18}$ reduced red cell deformability, ${ }^{14.19}$ and increased viscosity ${ }^{14.19}$ contribute to the final pathway of increased vessel permeability and ischaemia which result in the characteristic changes of diabetic retinopathy and nephropathy.

It is thought that diabetic control influences

Table III Other ocular complications of diabetic patients on dialysis

\begin{tabular}{lc}
\hline \multicolumn{1}{c}{ Complications } & Eyes \\
\hline Cataract & 10 \\
Band keratopathy & 2 \\
IIIrd N. palsy & 1 \\
Ischaemic optic neuropathy & 2 \\
Vitreous Hge* (anaemia/hypertension) & 2 \\
\hline
\end{tabular}

* Haemorrhage thought to be due to a combination of anaemia and hypertension. the progression of micro-angiopathy although this is still a source of some debate, ${ }^{14.19-36}$ while the duration of the disease process is also felt to be important ${ }^{20.28}$ Complications affecting different systems of the body occur at variable times but tend to run a parallel course. .2.36.37 $^{2}$

Renal failure is a risk factor for progressive retinopathy because of its associated hypertension and possibly also the multiple metabolic abnormalities, and it has been suggested that in the late stages there may be a rapid deterioration in patients' ocular status. ${ }^{38}$ It is common practice to start dialysis at an earlier stage in diabetics than in other patients with renal failure. Some studies have shown stabilisation of retinopathy following RRT, ${ }^{7.9}$ but progression may nevertheless occur. ${ }^{6.37}$ Improvement in the control of uraemia and hypertension lead to an improvement in retinopathy but this situation was observed in only one patient in this series who regressed from pre-proliferative to background retinopathy. While the relationship of diabetic control to the development of microangiopathic complications is still debatable, the evidence is increasing that strict metabolic control is desirable, ${ }^{20-29}$ although sudden 'tight control' following a long period of hyperglycaemia may be harmful. ${ }^{32-35}$ One explanation is that this causes a reduction in blood flow to organs which have become accustomed to a high flow rich in nutrients, thus causing ischaemic damage. This situation could arise at commencement of dialysis because of improved general health of the patient and closer supervision of blood glucose control. Twenty-eight patients in this study group had previously been noted to have a poor blood glucose control. Two patients (4 eyes) had been under observation with pre-proliferative changes but developed ischaemia requiring laser treatment after starting RRT and 4 eyes with regressed new vessels required further laser treatment after starting CAPD. Therefore it is important that all patients are seen by an ophthalmologist at the start of dialysis before rapid changes take place.

Treatment for diabetic nephropathy remains purely supportive-'renal replacement therapy'-either in the form of CAPD, HD or transplantation. Since CAPD was 
introduced into clinical practice this has allowed a rapid expansion in the number of diabetics being treated for renal failure. ${ }^{39}$ Previously haemodialysis, as the only dialysis choice available, posed particular problems in the diabetic patient, ${ }^{5,37.39}$ because of poor blood glucose control, difficulties in blood pressure control resulting from rapid fluid shifts and the requirement of heparinisation. CAPD does not have these problems while it is also cheaper and allows greater patient independence. The main complication of CAPD is peritonitis ${ }^{40-42}$ but most reports show that diabetics have only a slightly higher incidence than non-diabetics. ${ }^{2.43,44}$ Social rehabilitation is the aim of RRT in all patients and poor vision will hamper this objective. Blindness is still sometimes regarded as a contraindication to RRT, ${ }^{45}$ although nowadays, particularly with the introduction of CAPD, this is becoming much less common. Renal transplantation offers a considerably better quality of life in comparison with dialysis as well as being much cheaper. Also graft survival is almost as good in young insulin dependent diabetics as in non-diabetics of similar age range. ${ }^{9}$

In contrast to this supportive therapy modern management of diabetic retinopathy aims at both preserving and restoring vision in early and late stages of disease using laser photocoagulation $^{46-52}$ and vitreoretinal surgery ${ }^{53-57}$ respectively. Laser photocoagulation has proved its efficacy, but only when given at the appropriate time. ${ }^{46}$ Diabetic retinopathy remains the commonest cause of blindness in the working population in the West of Scotland ${ }^{58}$ This was reflected in our series in that 8 eyes were not identified as having retinopathy until they were untreatable and 5 eyes which did receive laser treatment were not seen at the optimum stage and they all had poor visual results. Two patients ( 4 eyes) first saw an ophthalmologist after commencement of RRT and both had extensive new vessel formation by that time. The importance of screening programmes and education must be emphasised to reduce the morbidity from this complication which is the most amenable to treatment. ${ }^{59-61}$ Fewer diabetics should lose sight in the future with the introduction of such screening programmes.
Vitreo-retinal surgery is time consuming and expensive and in this high risk group has an improvement rate of only between 46 to 75 per cent. ${ }^{53-57}$ It is therefore only directed at the poorly sighted diabetic patient with long standing vitreous haemorrhage or 'straightforward' traction retinal detachment which has developed a tear or involves the macula. The duration of the anaesthetic may be extensive and the general condition of the patient must be relatively good. Four patients in this series underwent surgery, but only one patient did well. In this case the vision was improved from $6 / 60$ to $6 / 12$ in the better eye allowing the patient to return to work. The success rate of surgery is normally higher and this difference probably reflects the small number of patients in this study.

The ocular complications of renal failure and its treatment which are well documented $^{62-65}$ also occur in diabetics and must be treated appropriately. There was no case of steroid induced glaucoma or CMV retinitis; however corneal calcification occurred in one patient and cataract developed in 10 .

\section{Conclusions}

Diabetics are not all blind by the time they reach end-stage renal failure. Patients should be seen by an ophthalmologist on commencement of RRT as sudden changes in metabolic control may have detrimental effects on retinopathy which require treatment. However in the majority RRT does not cause visual deterioration and may result in improvement.

We would like to thank all ophthalmologists in the West of Scotland who provided essential background information on many patients; the secretarial and reception staff at the renal unit for their assistance and Mrs Katy MacAulay for typing the manuscript.

\section{References}

${ }^{1}$ Friedman EA and L'Esperance FA (Eds): Diabetic Renal-Retinal Syndrome. New York: Grune and Stratton. 1980.

${ }^{2}$ Amir P, Khanna R, Leibel B et al: Continuous ambulatory peritoneal dialysis in diabetics with end-stage renal disease. N. Eng. J. Med. 1982; 306: $625-30$.

${ }^{3}$ Rottembourg J, de Groc F, Poignet JL, Legrain M: Is continuous ambulatory peritoneal dialysis the 
best dialysis choice for insulin dependent diabetics? Proc. EDTA. 1982; 19: 215-26.

${ }^{4}$ Joint Scandinavian Report: Renal transplantation in insulin dependent diabetics. Lancet 1978; 28: 915-17.

${ }^{5}$ Katirtzoglou A: Peritoneal dialysis in diabetics. In: Diabetic Renal-Retinal Syndrome, Friedman EA and L'Esperance FA (Eds). New York: Grune and Stratton. 1980; 3090-15.

${ }^{6}$ Ramsay RC, Cantrill HL, Kinyoun JL et al: Visual status in diabetic renal failure. In: Diabetic Renal-Retinal Syndrome, Friedman EA and L'Esperance FA (Eds). New York: Grune and Stratton. 1980; 309-15.

${ }^{7}$ Ramsay RC, Knobloch WH, Barbosa JJ et al: The visual status of diabetic patients after renal transplantation. Am. J. Ophthalmol. 1979, 87: 30510.

${ }^{8}$ Gonzalez-Carillo M, Moloney A, Bewick M, Parsons V, Rudge CT, Watkins PJ: Renal transplantation in diabetic nephropathy. Br. Med. J. 1982; 285: 1713-16.

${ }^{9}$ Najarian JS, Sutherland DER, Simmons RL et al: Ten year experience with renal transplantation in juvenile onset diabetics. Ann. Surg. 1979; 190: 487-500.

${ }^{10}$ Tunbridge WMG: Factors contributing to deaths of diabetics under fifty years of age. Lancet 1981; 2: 569-72.

11 Watkins PJ: Diabetic nephropathy-prevalence, complications and treatment. Diabetic Medicine 1985; 2: 7-12.

${ }^{12}$ Deckert T, Poulson JE, Larsen M: Prognosis of diabetics with diabetes onset before age of 31 . Diabetologia 1978; 14: 463-77.

${ }^{13}$ Cameron JS: The management of diabetic renal failure in the United Kingdom. Diabetic Nephropathy 1983; 2: 1-2.

${ }^{14}$ Little HL: Alterations in blood elements in the pathogenesis of diabetic retinopathy. Ophthalmology 1981; 88: 647-54.

15 Williamson JR, Kilo C: Basement-membrane thickening and diabetic microangiopathy. Diabetes 1976; 25: 925-7.

${ }^{16}$ Parving H.-H, Viberti GC, Keen H, Christiansen JS, Larssen NA: Haemodynamic factors in the genesis of diabetic microangiopathy. Metabolism 1983; 32: 943-9.

${ }^{17}$ Cunha-Vaz JG: Pathophysiology of diabetic retinopathy. Br. J. Ophthalmol. 1978; 62: 351-55.

${ }^{18}$ Dobbie JG, Kwaan HC, Colwell J, Suwanwela N: Role of platelets in pathogenesis of diabetic retinopathy. Arch. Ophthalmol. 1974, 91: 107-9.

${ }^{19}$ Little HL: Abnormal blood rheology in the pathogenesis of diabetic retinopathy. In: Diabetic Renal-Retinal Syndrome. Friedman EA and L'Esperance FA (Eds). New York: Grune and Stratton $1980 ; 77-81$.

${ }^{20}$ Klein R, Klein BEK, Moss SE, Davis MD, De Mets DL: The Wisconsin Epidemiologic Study of diabetic retinopathy II. Prevalence and risk of diabetic retinopathy when age at diagnosis is less than 30 years. Arch. Ophthalmol. 1984; 102: 520-6.

${ }^{21}$ Cahill GF, Etzwiler DD, Freinkel N: 'Control' and diabetes. N. Eng. J. Med. 1976; 294: 1004-5.

${ }^{22}$ Friberg TR, Rosenstock J, Sanborn G, Vaghefi A, Raskin P: The effect of long-term near normal glycaemic control on mild diabetic retinopathy. Ophthalmology 1985; 92: 1051-8.

${ }^{23}$ Doft BH, Kingsley LA, Archard TJ, Kuller L, Drash A, Becker D: The association between long-term diabetic control and early retinopathy. Ophthalmology 1984; 91: 763-9.

${ }^{24}$ Steno Study Group: Effect of six months of strict metabolic control on eye and kidney function in insulin dependent diabetics with background retinopathy. Lancet 1982; 1: 121-4.

${ }^{25}$ Steinmetz PR, Balko C: The Sorbital pathway and the complications of diabetes. N. Engl. J. Med. 1973; 288: 831-6.

${ }^{26}$ Knowler WC, Bennett PH, Ballintine EJ: Increased incidence of retinopathy in diabetics with elevated blood pressure. N. Engl. J. Med. 1980; 302: 645-50.

${ }^{27}$ Steinmetz PR, Balko C: Biochemistry of the renal glomerular basement membrane and its alterations in diabetes mellitus. N. Engl. J. Med. 1973; 288: $1337-42$.

${ }^{28}$ Schantzlin DT, Jay WM, Fritz KJ, Tripathi RC, Gonen B: Haemoglobin A, and diabetic retinopathy. Am. J. Ophthalmol. 1979; 88: 1032-8.

${ }^{29}$ Palmberg P, Smith M et al: The natural history of retinopathy in insulin dependent juvenile-onset diabetes. Ophthalmology 1981; 88: 613-18.

${ }^{30}$ Adnitt PI and Taylor E: Progression of diabetic retinopathy. Relationship to blood glucose. Lancet 1970; 1: 652-4.

${ }^{31}$ Siperstein MD, Foster DW, Knowles HC, Levine R, Madison LL, Roth J: Control of blood glucose and diabetic vascular disease. N. Eng. J. Med. 1977; 296: 1060-3.

${ }^{32}$ Dandona P, Bolger JP, Boag F, Fonesca V, Abrams JD: Rapid development and progression of proliferative retinopathy after strict diabetic control. Br. Med. J. 1985; 290: 895-6.

${ }^{33}$ Lorenzi M, Goldbanns MH, Spencer EM, Cheney $\mathrm{C}$ : Improved diabetic control and retinopathy. $N$. Eng. J. Med. 1983; 308: 1600.

${ }^{34}$ Dahl-Jorgensen K, Brinchmann-Hansen D, Hansseen KF, Sandvik L, Aagenaes, O, Aker diabetes group: Rapid tightening of blood glucose control leads to transient deterioration of retinopathy in insulin dependent diabetes mellitus-the Oslo study. Br. Med. J. 1985; 290: 811-5.

${ }^{35}$ Lawitzen T, Frost-Larsen K, Larsen $\mathrm{HW}$ and Deckert T: Effect of 1 year of near-normal blood glucose levels on retinopathy in insulin dependent diabetics. Lancet 1983; 1: 200-4.

${ }^{36}$ Barnett AH, Dallinger K, Jennings P, Fletcher J, Odugbesan $\mathrm{O}$ : Microalbuminuria and diabetic retinopathy. Lancet 1985; 1: 53-4.

${ }^{37}$ D'Elia JA, Kaldany A, Miller PG, Abouriz KN, Weinrauch LA: Diabetic nephropathy. In: Joslin's Diabetes Mellitus. Marble A, Krall LP, 
Bradley RF, Christlieb AR and Soeldner JS (Eds). Philadelphia: Lea and Febiger 1985; 63564.

${ }^{38}$ Aiello LM, Rand LI, Sebestyen JG: The Eyes and Diabetes. In: Joslin's Diabetes Mellitus. Marble A, Krall LP, Bradley RF, Christlieb AR and Soeldner JS (Eds). Philadelphia: Lea and Febiger 1985; 615-22.

${ }^{39}$ Junor BJR: Continuous ambulatory peritoneal dialysis. Scot. Med. J. 1986; 31: 69-71.

${ }^{40}$ Tsakiris DJ, Smith WGJ, Briggs JD, Junor BJR: Continuous ambulatory peritoneal dialysis: a three year experience. Scot. Med. J. 1986; 31: 79-84.

${ }^{41}$ Smith WGJ, Tsakiris DJ, Junor BJR et al: Peritonitis in continuous ambulatory peritoneal dialysis. Scot. Med. J. 1986; 31: 85-9.

${ }^{42}$ Chan MK, Baillod RA, Chuah P et al: Three years experience of continuous ambulatory peritoneal dialysis. Lancet 1981; 1: 1409-12.

${ }^{43}$ Flynn CT: Long-term continuous ambulatory peritoneal dialysis. Proc. EDTA 1983; 20: 700-4.

${ }^{44}$ Flynn CT: Why blind diabetics with renal failure should be offered treatment. Br. Med. J. 1983; 287: $1177-8$.

${ }^{45}$ Challah S, Wing AJ, Baver R, Morris RW, Schroeder SA: Negative selection of patients for dialysis and transplantation in the United Kingdom. Br. Med. J. 1984; 288: 1119-22.

${ }^{46}$ Hercules BL, Gayed II, Lucas SB, Jeacock J: Peripheral retinal ablation in the treatment of proliferative diabetic retinopathy: a three year interim report of a randomised, controlled study using the argon laser. Br. J. Ophthalmol. 1977; 61: 555-63.

47 The Diabetic Retinopathy Study Research Group: Photocoagulation treatment of proliferative diabetic retinopathy: the second report of diabetic retinopathy study findings. Am. J. Ophthalmol. 1977; 85: 82-104.

${ }^{48}$ James WA, L'Esperance FA: Treatment of optic nerve neovascularization by extensive retinal photocoagulation. Am. J. Ophthalmol. 1974; 78: 939-47.

${ }^{49}$ Little HL, Zweng HC, Jack RL, Vassiliadis A: Techniques of argon laser photocoagulation of diabetic disc new vessels. Am. J. Ophthalmol. 1976; 82: $675-83$.

${ }^{50}$ The Diabetic Retinopathy Study Research Group: Preliminary Report on effects of photocoagula- tion therapy. Am. J. Ophthalmol. 1976; 81: 38395.

${ }^{51}$ Little HL: Treatment of proliferative diabetic retinopathy. Long-term results of argon laser photocoagulation. Ophthalmology 1985; 92: 279-83.

52 The Diabetic Retinopathy Study Research Group: Photocoagulation treatment of proliferative diabetic retinopathy. Ophthalmology 1981; 88: 583600.

${ }^{53}$ The Diabetic Retinopathy Study Group: Photocoagulation treatment of proliferative diabetic retinopathy. The Second Report of Diabetic Retinopathy Study Findings. Ophthalmology 1978; 85: 82-106.

${ }^{54}$ Aaberg TM: Pars plana vitrectomy for diabetic traction retinal detachment. Ophthalmology 1981; 88: 639-42.

${ }^{55}$ Barrie T, Feretis E, Leaver P, McLeod D: Closed microsurgery for diabetic traction macular detachment. Br. J. Ophthalmol. 1982; 66: 754-8.

${ }^{56}$ Aaberg TM: Clinical results in vitrectomy for diabetic traction retinal detachment. Am. J. Ophthalmol. 1979; 88: 246-53.

${ }^{57}$ McLeod D, Leaver PK, Feretis E: Vitrectomy for severe diabetic eye disease. Trans. Ophthalmol. Soc. UK 1980; 100: 291-8.

${ }^{58}$ Machemer $\mathrm{R}$ and Blankenship S: Vitrectomy for proliferative diabetic retinopathy associated with vitreous haemorrhage. Ophthalmology 1981; 88: 643-6.

${ }^{59}$ Ghafour IM, Allan D, Foulds WS: Common causes of blindness and visual handicap in the West of Scotland. Br. J. Ophthalmol. 1983; 67: 209-13.

${ }^{60}$ Kohner EM: The solution of the problem. Trans. Ophthalmol. Soc. UK 1978; 98: 299-302.

${ }^{61}$ Foulds WS, McCuish A, Barrie T et al: Diabetic retinopathy in the West of Scotland: It's detection and prevalence and the cost effectiveness of a proposed screening programme. Health Bulletin 1983; 41/6: 318-26.

62 Burns-Cox CJ, Dean Hart JC: Screening of diabetics for retinopathy by ophthalmic opticians. $B r$. Med. J. 1985; 290: 1052-4.

${ }^{63}$ Porter R, Crombie AL, Gardner PS, Uldall RP: Incidence of ocular complications in patients undergoing renal transplantation. Br. Med. J. 1972; 3: 133-6.

${ }^{64}$ Berkowitz JS, David DS, Sakai S et al: Ocular complications in renal transplant recipients. Am. J. Med. 1973; 55: 492-5.

${ }^{65}$ Editorial: Eyes after renal transplantation. Br. Med. J. 1972; 3: 127-8. 